\title{
VoCALIC Alternations IN THE HistORY OF IRISH
}

\author{
KRZYSZTOF JASKUŁA
}

\section{Introduction}

Vocalic alternations occur in many languages, both past and present, and the reason why they do is on many occasions contemporary and contexttriggered, i.e. phonological. Sometimes, however, the cause of vocalic changes cannot be associated with the phonological context. In this paper we will look at the alternations of short vowels in the history of the Irish language with a view to discovering whether these changes can be perceived as synchronic and context-motivated or, rather, as belonging to morphophonology, i.e. being diachronically determined.

This work is organised as follows. First, we will become acquainted with the basic tenets of Government Phonology, a theory of representations in the spirit of which the ensuing analysis will be conducted. Second, recent approaches to the issue of short vowel alternations in two dialects of Modern Irish (Munster and Connemara) will be presented and discussed. Third, alternating short vocalic expressions of Old Irish will be examined, which will be accompanied with an excursion to prehistoric times. Finally, conclusions as regards the nature of Irish alternations will be offered.

\section{Vowels in Government Phonology}

Government Phonology (Kaye, Lowenstamm and Vergnaud 1990, Charette 1990, Gussmann and Kaye 1993, Harris 1994) is a theory of representations in which all phonological phenomena are believed to arise from a few cross-linguistic principles and language-specific parameters. For instance, it is assumed that all nuclei license the preceding onsets, that onsets and nuclei can be empty, that relations of government obtain between phonological objects and that all sounds of speech are composed of phonological elements. For our analysis it is important to concentrate on this last issue.

Phonological elements or primes are the smallest phonological units which can be pronounced alone. There are three vocalic elements which can occur either by themselves or in combinations with other elements. Consider the following simplified scheme: 
(1)

\begin{tabular}{|c|c|c|c|c|c|c|c|}
\hline $\begin{array}{l}\text { ELEMENTS AND } \\
\text { COMBINATIONS }\end{array}$ & $\mathrm{A}$ & $\mathrm{I}$ & $\mathrm{U}$ & $\mathrm{A}+\mathrm{I}$ & $\mathrm{A}+\mathrm{U}$ & $\mathrm{U}+\mathrm{I}$ & $\mathrm{A}+\mathrm{I}+\mathrm{U}$ \\
\hline VOWELS & {$[\mathrm{a}]$} & {$[\mathrm{i}]$} & {$[\mathrm{u}]$} & {$[\mathrm{e}]$} & {$[\mathrm{o}]$} & {$[\mathrm{y}]$} & {$[œ]$} \\
\hline
\end{tabular}

Thus, if we pronounce the elements (I), (A) and (U) in isolation, we will obtain the cardinal vowels [i], [a] and [u], respectively, while fusions of primes result in other vocalic expressions. The phonetic details of all vowels are language-dependent. For example, in one phonological system (A) may be realised as [a], [a] or [æ], while a combination (A, I) may be pronounced as $[e],[\varepsilon]$ or even [æ], etc. In many tongues, such as all the dialects of Irish, both past and present, (I) and (U) do not combine and front rounded vowels are excluded from such phonological systems.

As regards the graphic representation of words, vowels are linked to nuclei, while consonants to onsets. Consider two Polish words, [Exo] echo - 'echo' and [zima] zima - 'winter' in which the vowels are represented by elements:
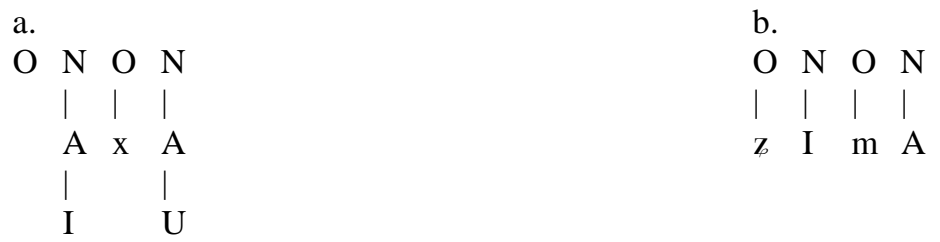

We can observe that in (2a) the vowels [ $[\varepsilon]$ and [o] are composed of (A, I) and $(A, U)$, respectively, while in (2b) the vowel [i] equals (I) and [a] includes (A).

Finally, it should be noticed that combinations of elements may represent asymmetric relations. In other words, one element may be viewed as more important for the quality of a given segment and may be called 'head', the other(s) being complementary - 'operator(s)'. Hypothetically, in a system with two types of $e$, we may say that [e] equals (A, I), because it is a vowel closer to [i], while $[\varepsilon]$ is composed of ( $\underline{\mathrm{A}}, \mathrm{I})$, since it is a lower vowel. All such relations must not be taken a priori but have to be established as a result of a thorough phonological analysis of a particular system.

\section{Alternations in Munster Irish}

The inventory of short vowels is composed of three front vowels, that is [i], [e] and [a], plus three back vowels, namely [a], [o] and [u]. Cyran (1997: 
40ff.) presents the following picture of the most important alternations of short vowels in stressed syllables in Munster Irish: ${ }^{1}$

(3) EXAMPLES

a. [muk] muc

b. [sop] sop [trodə] trod

c. [fiar] fear [f $\mathrm{f}^{\mathrm{i}}$ asə] feasa

d. [dias] deas

e. [obiri ${ }^{\mathrm{i}}$ obair [mik $\left.{ }^{\mathrm{i}}\right]$ muic $^{2}$ [pih'ə] puithe [sip ${ }^{\mathrm{i}}$ ] soip [trid ${ }^{\mathrm{i}}$ troid [firi ${ }^{\mathrm{i}}$ ] fir [ $\mathrm{f}^{\mathrm{i}}$ is] fios [diefə] deise [ebiirio] oibre
GLOSS

- 'pig'/dat.sg.

- 'breeze'/gen.sg.

- 'wisp'/gen.sg.

- gen.sg./'fight'

- 'man'/gen.sg.

- gen.sg./'knowledge'

- 'nice'/gen.sg.fem.

- 'work'/gen.sg.
TYPE

[u $-\mathrm{i}]$

[o - i]

[a - i]

$[\mathrm{a}-\mathrm{e}]$

[o-e]

There are five major types of alternations in Munster Irish. In the cases in (3d, e) the impact of the vocalic ending may be blamed for the vowel changes. In (3a-c), however, we observe that the vowels change irrespective of vocalic endings. At this juncture, Cyran (1997) proposes that what primarily influences the quality of the leftmost (stressed) vowel is the quality of the following consonant, i.e. either palatalised (i-quality) or velarised (u-quality). He also argues that every consonant shares either of these qualities with the following nucleus, be it empty or filled. An illustration of what happens to the stressed vowels represented in (3a) is provided below:

(4)

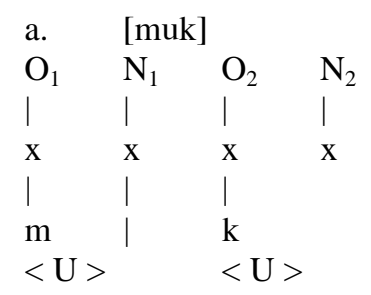

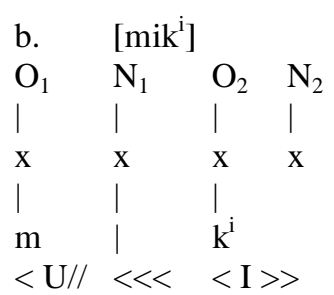

In (4a) the onset $\left(\mathrm{O}_{1}\right)$ shares $(<>)$ the element (U) with the following nucleus. The same goes for the $\left(\mathrm{O}_{2} \mathrm{~N}_{2}\right)$ sequence. In (4b) the pair of $\left(\mathrm{O}_{2} \mathrm{~N}_{2}\right)$ shares the element (I), which spreads leftwards but encounters a buffer (//) in the shape of the velarised onset $\left(\mathrm{O}_{1}\right)$. So, the nucleus $\left(\mathrm{N}_{1}\right)$ is affected by $I$-spreading and the resulting vowel is [i], but the preceding onset remains intact, i.e. un-palatalised. Considering the alternation of [pu] vs. [pih'i 2 ], the schwa in the last syllable does not matter and the process looks like that

\footnotetext{
${ }^{1}$ Due to the lack of space, the present analysis will concern only the selected vowels in stressed syllables, although the discussion of vowels in unstressed ones would not bring dramatically different results.

2 The superscript [i] is used in the data to indicate palatalisation.
} 
depicted in (4) above in that the element (I) spreads leftwards from the second onset to change the nucleus but not its onset.

In (3b) the situation is similar, but not identical. In particular, the vowel [o] in [sop] is composed of (A, U), both onsets sharing the element (U) with their nuclei. As a result of $I$-spreading from the end of the word, the vowel in [sip $\left.{ }^{i}\right]$ is [i], the element (A) in the first nucleus is suppressed, but the first onset stays unaffected by the spreading.

When we turn to the examples in (3c), the situation is explained by

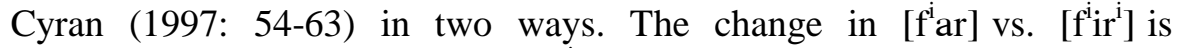
straightforward. Specifically, in [fiar] the element (A) belongs to $\left(\mathrm{N}_{1}\right)$ which shares the prime (I) with $\left(\mathrm{O}_{1}\right)$. No I-spreading occurs since the following $\mathrm{O}-\mathrm{N}$ sequence is specified by (U). In [fi $\left.\mathrm{fir}^{\mathrm{i}}\right]$ the process of $I-$ spreading from the end of the word is at work and (A) no longer remains in the representation:

(5)

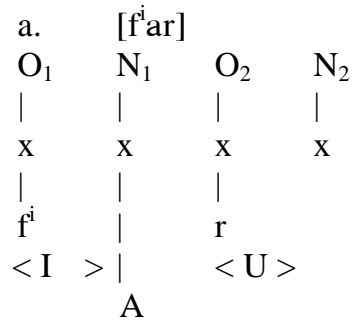

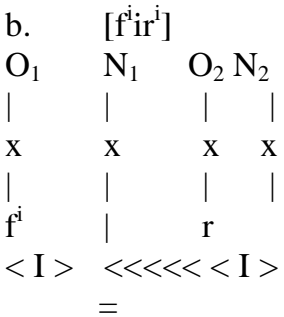

A

Thus, the form in (5a) is treated as basic, while in (5b) we are dealing with a derivative, because the prime (A) belongs to the representation but it is delinked from $\left(\mathrm{N}_{1}\right)$. As for the alternation of [ $\mathrm{f}^{\mathrm{i}}$ is] vs. [ $\mathrm{f}^{\mathrm{i}}$ asə], Cyran's account is as follows:

(6)

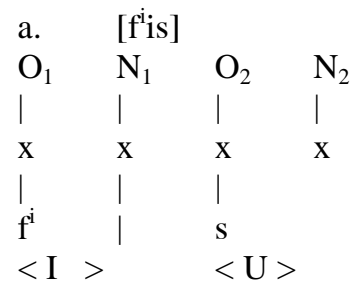

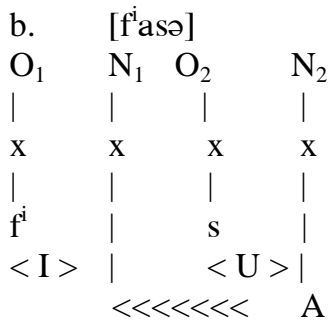

In [ $\mathrm{f}^{\mathrm{i}} \mathrm{is}$ ] the first $\mathrm{O}-\mathrm{N}$ sequence shares the prime (I). In [ $\mathrm{f}^{\mathrm{i} a s}$ ] the element (A) from under $\left(\mathrm{N}_{2}\right)$ spreads leftwards to affect $\left(\mathrm{N}_{1}\right)$ and create the vowel [a]. In this case the final schwa is important, unlike that in [pih ${ }^{\mathrm{i}}$ ], in that it provides the preceding nucleus with (A), which is connected with the fact 
that the onset $\left(\mathrm{O}_{2}\right)$ in (6b) is not palatalised. Actually, this exemplifies a change from the basic [i] to the derived [a].

Finally, let us move on to (3d, e). In [dias] vs. [die eə], Cyran (1997: 61) proposes that (A) can spread from schwas preceded by palatalised onsets but here the phenomenon involving the activity of this prime should actually be called $A$-support, since (A) supports the presence of its mate in the preceding nucleus:
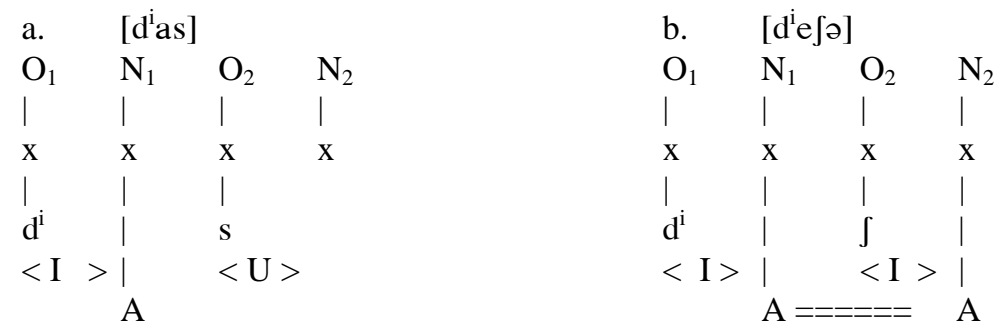

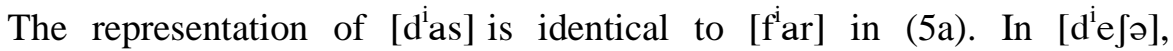
conversely, we see two O-N sequences specified by (I). The final schwa is a source of $A$-support for the same prime under $\left(\mathrm{N}_{1}\right)$. No such support is needed in (7a) because the element (U) cannot enter $\left(\mathrm{N}_{1}\right){ }^{3}$

The ultimate pair, that is [obiri] vs. [ebiri ${ }^{\mathrm{i}}$ ], appears problematic for Cyran, since no mechanism employed in the other examples works here. Besides, the alternation of [o - e] is rare and exceptional in Irish. Thus, although a solution is proposed (Cyran 1997: 77), the author finds it unsatisfactory.

What should also be noted is that there are non-alternating vowels in Munster Irish, e.g. [kat] cat vs. [kat ${ }^{\mathrm{i}}$ ] cait - 'cat'/gen.sg. Such opaque vowels are treated as invariably headed.

Thus, although this analysis of vowel alternation in Munster Irish practically solves the problem, a few questions remain unanswered. The distinction between spreading and support is unclear. Moreover, why does the vague idea of idea of sharing not necessarily find confirmation in the phonetic shape of vowels? In other words, why do the shared primes (I) and (U) have no stable impact on the quality of the nuclei? Thus, why should [a] in [dias] and [e] in [d $\left.\mathrm{d}^{\mathrm{i}} \int \mathrm{e}\right]$ have the same element structure? Finally, why should the forms of the nominative case be viewed as basic and why do we have an impression that the idea of derivation is present in a nonderivational framework?

\footnotetext{
${ }^{3}$ In fact, Cyran's (1997) analysis is more complicated. He proposes that some segments resistant to spreading are headed, which is neglected here for the sake of greater clarity because Munster Irish vowels which never alternate are also headed.
} 
Consequently, this synchronic analysis of vocalic alternations is complicated and logical but it hinges on very ingenious and daring assumptions. Without these, which may be perceived as theoretically dubious, a few solutions are difficult to defend.

\section{Alternations in Connemara Irish}

In Connemara Irish (Bloch-Rozmej 1998), there are three short front vowels: [i], [e], [æ], and three back vowels: [a], [o], [u]. Below let us consider a selection of the most important types of vocalic changes:

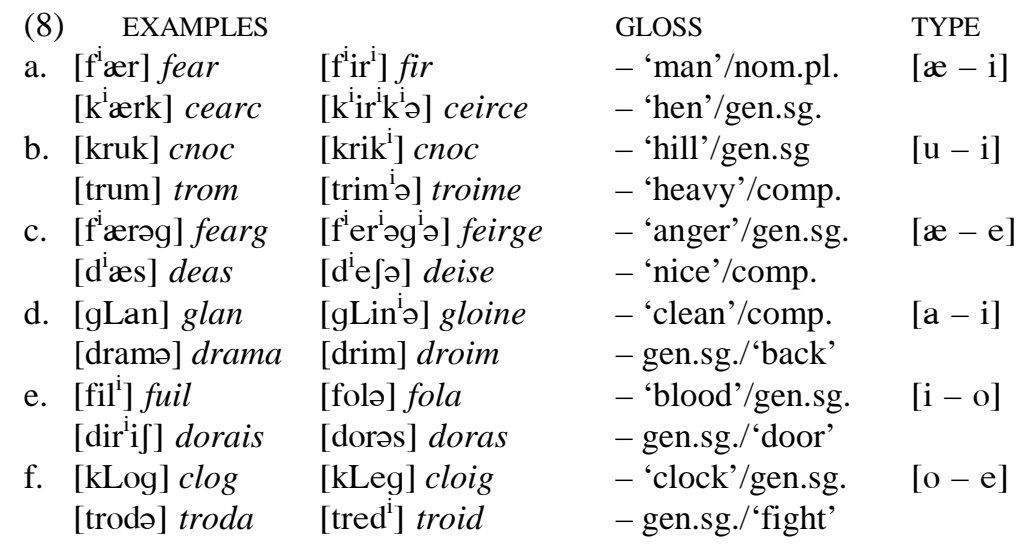

Bloch-Rozmej (1998) employs nearly the same mechanisms as those used by Cyran (1997), namely element sharing, spreading and support. What is slightly different is the notion of head-operator inversion as well as the idea that most alternations presented above have a specified direction of change. In particular, the alternation of, say, [o - e] from (8f) above, is a change from [o] to [e] in [kLog] $\rightarrow$ [kLeg], where the element (I) fronts the vowel, but in $\left[\right.$ tred $\left.^{\mathrm{i}}\right] \rightarrow$ [trodə] the change is from [e] to [o] and the prime (U) plays the most important role here. If we look at changes such as [æ-e] from (8c) and [æ-i] from (8a), these alternations involve the headoperator inversion.

Without explaining the details of element structures of vowels, consider the following justification of a few of these developments (Bloch-Rozmej 1998: 54-65):

(9) TYPE
a. $[\mathrm{o}] \rightarrow[\mathrm{e}$
$[\mathrm{kLog}] \rightarrow[\mathrm{kLeg}]$
b. $[\mathrm{e}] \rightarrow[\mathrm{o}] \quad\left[\right.$ tred $\left.^{\mathrm{i}}\right] \quad \rightarrow$ [trodə]

DESCRIPTION

$(\underline{\mathrm{U}}, \mathrm{A} \rightarrow \underline{\mathrm{I}}, \mathrm{A})$

I becomes head, $U$ is suppressed

$(\underline{I}, \mathrm{~A} \rightarrow \underline{\mathrm{U}}, \mathrm{A})$

$\mathrm{U}$ becomes head, I is suppressed 

c. $[æ] \rightarrow[e] \quad\left[f^{\mathrm{i}} æ r \partial g\right] \rightarrow\left[f^{\mathrm{i}} \operatorname{er}^{\left.\mathrm{i} \partial g^{\mathrm{i}} \partial\right]}\right.$
$(\mathrm{I}, \underline{\mathrm{A}} \rightarrow \underline{\mathrm{I}}, \mathrm{A})$
head-operator inversion
d. $[æ] \rightarrow[\mathrm{i}] \quad\left[\mathrm{f}^{\mathrm{i}} \mathrm{x}\right] \quad \rightarrow\left[\mathrm{f}^{\mathrm{i}} \mathrm{ir}^{\mathrm{i}}\right]$
$(\mathrm{I}, \underline{\mathrm{A}} \rightarrow \underline{\mathrm{I}})$
head-operator inversion,
A is suppressed

All this is possible if element sharing is a given. For example, in [tred $\left.{ }^{\mathrm{i}}\right] \rightarrow$ [trodə] the vowel [e] is composed of (I, A) but the element shared by the leftmost $\mathrm{O}-\mathrm{N}$ sequence is $(\mathrm{U})$ because the onset is not palatalised. So the elements occurring under the nucleus in [tred ${ }^{\mathrm{i}}$ ] should in fact be all three (I, A, U), which is not mentioned in the description because (I) and (U) do not combine in Connemara and (U) specifies the quality of the first onset, while (I) is found in the nucleus. Then (U) becomes promoted to the head position in the left-hand nucleus in [trodə], while (I) is not simply demoted but deleted. The remaining cases are accounted for in a similar fashion.

There are also alternations involving the deletion of one prime and the addition of others, e.g. [u $\rightarrow \mathrm{i}]$ in $[\mathrm{kruk}] \rightarrow\left[\mathrm{krik}^{\mathrm{i}}\right]$ from $(8 \mathrm{~b})$, $[\mathrm{i} \rightarrow \mathrm{a}]$ in [drim $] \rightarrow$ [dramə] from (8d) and $[\mathrm{i}-\mathrm{o}]$ in [fil $\left.{ }^{\mathrm{i}}\right] \rightarrow[$ folə] from (8e) above. These are schematised below:
(10) TYPE
EXAMPLES
a. $[\mathrm{u} \rightarrow \mathrm{i}]$
$[\mathrm{kruk}] \rightarrow\left[\mathrm{krik}^{\mathrm{i}}\right]$
DESCRIPTION
b. $[\mathrm{i} \rightarrow \mathrm{a}]$
$[$ drim $] \rightarrow[$ dramə]
$(\underline{\mathrm{U}} \rightarrow \underline{\mathrm{I}})$
$\mathrm{I}$ becomes head, $\mathrm{U}$ is suppressed
c. $[\mathrm{i}-\mathrm{o}]$
$\left[\right.$ fiil $\left.^{\mathrm{i}}\right] \rightarrow[$ folə]
$(\underline{\mathrm{I}} \rightarrow \underline{\mathrm{A}})$
A becomes head, $\mathrm{I}$ is suppressed
$(\underline{\mathrm{I}} \rightarrow \mathrm{A}, \underline{\mathrm{U}})$
$\mathrm{U}$ becomes head, $\mathrm{A}$ is added,
I becomes suppressed

These changes are described in a dynamic, derivational fashion, which is slightly strange in a non-derivational model such as GP. The order of changes also raises doubts. For example, why should the form [fili ${ }^{\mathrm{i}}$ from (10c) be treated as basic, while [folə] as derived? Is it only because [fili ${ }^{\mathrm{i}}$ is the nominative?

All in all, these twin analyses of two dialects of Modern Irish have one serious drawback. In particular, their authors try to explain everything from the synchronic perspective and they use every possible tool to prove that all phenomena are phonological by nature. This assumption will be questioned in the remaining part of this paper. 


\section{Old Irish Vocalic Alternations - Three Analyses}

The short vowels of Old Irish can also be divided into two indubitable sets: the front vowels [i], [e], and the back vowels [u], [o]. The vowel represented by the symbol $a$ might seem uncertain but, since it apparently never occurs following a palatalised onset word-initially, we can assume that it is a non-front vowel [a]. ${ }^{4}$ Before considering the most important Old Irish alternations of short vowels in stressed syllables, note that it was highly unlikely for a back vowel to follow a palatalised onset and, conversely, it was rather impossible for a front vowel to be preceded by a non-palatalised consonant: ${ }^{5}$

\section{(11) Nominative Sg. Genitive Sg. Dative Sg. Accusative Pl. Gloss} a.

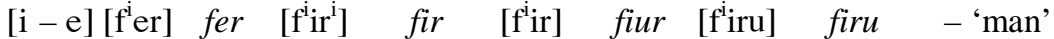
[g $\left.\mathrm{g}^{\mathrm{i}} \mathrm{i} \mathrm{eN}\right]$ glenn $\left[\mathrm{g}^{\mathrm{i}} \mathrm{i}^{\mathrm{i}} \mathrm{N}^{\mathrm{i}} \mathrm{e}\right]$ glinne $\left[\mathrm{g}^{\mathrm{i}} \mathrm{i}^{\mathrm{i}} \mathrm{N}^{\mathrm{i}}\right]$ glinn $\left[\mathrm{g}^{\mathrm{i}} \mathrm{l}^{\mathrm{i}} \mathrm{N}^{\mathrm{i}} \mathrm{e}\right]$ glinne - 'valley'
$\left[\mathrm{R}^{\mathrm{i}} \mathrm{iNd}\right]$ rind $\left[\mathrm{R}^{\mathrm{i}} \mathrm{eNdo}\right]$ rendo $\left[\mathrm{R}^{\mathrm{i}} \mathrm{iNd}\right]$ rind $\left[\mathrm{R}^{\mathrm{i}} \mathrm{iNd}\right]$ rind - 'star' b.

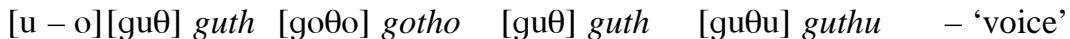 [son] son [sun'] suin [sun] sun [sunu] sunu - 'sound' [muri $\left.{ }^{\mathrm{i}}\right]$ muir [moro] moro [mur $\left.{ }^{\mathrm{i}}\right]$ muir [mur' ${ }^{\mathrm{i}}$ ] muire - 'sea'
c.
$[\mathrm{a}-\mathrm{u}][\mathrm{kraN}]$ crann $\left[\mathrm{kruN}^{\mathrm{i}}\right]$ cruinn $[\mathrm{kruN}]$ crunn $[\mathrm{kraNa}]$ cranna - 'tree' [brat] bratt [brut'] bruitt [brut] brutt - 'cloak'

d.

$$
\begin{aligned}
& \text { [a-e][day } \left.{ }^{\mathrm{i}}\right] \text { daig [d'eyo] dego [day'] daig - 'fire' } \\
& \text { [gray } \left.\left.\left.{ }^{\mathrm{i}}\right] \text { graig [g }{ }^{\mathrm{i}} \mathrm{r}^{\mathrm{i}} \mathrm{eyo} / \mathrm{a}\right] \text { grego/a [gray }{ }^{\mathrm{i}} \mathrm{e}\right] \text { graige - 'horses' } \\
& \text { (coll.) }
\end{aligned}
$$

In (11a, b), the picture seems relatively clear: the root vowel is always [i] in (11a) and [u] in (11b) unless there is the mid back vowel [o] in the next syllable. The problematic cases are the nominative singular [ $\left.f^{i} e r\right],\left[g^{i} 1^{i} e N\right]$ and [son], because no vowel follows. If [o] follows, the root vowel surfaces as [e] in (11a) and as [o] in (11b). As for the aforementioned difficult cases, their analysis may go three different ways (see below).

The examples in (11c, d) show that the vowel [a] can alternate either with [u] (11c) or with [e] (11d). The alternation with [u] makes a little sense in the dative, e.g. [kruN], where the final consonant might be

\footnotetext{
${ }^{4}$ The exact phonetic quality of this, that is, whether it is realised as [a] or [a], seems unimportant phonologically.

${ }^{5}$ This transcription is based on a comprehensive analysis of consonant qualities offered by Jaskuła (2006).
} 
velarised, i.e. specified with the prime (U), but it is totally incomprehensible in the genitive, e.g. $\left[\mathrm{kruN}^{\mathrm{i}}\right]$, where the final consonant is clearly palatalised, i.e. determined by (I). The obvious problems are: (i) what happens to the element (A), clearly responsible for the quality of the radical vowel, and (ii) what is the source of the vowel [u] if the final consonant is palatalised? It appears that the root vowel in the nominative is replaced by another root vowel in the oblique cases, in which case we deal with a kind of ablaut. As regards the alternation [a - e], it seems that the radical vowel of the nominative is replaced by [i] in the other cases and that this [i] is lowered to [e] if there is the mid back vowel [o] in the following syllable. So the pattern seems to partly follow that in (11a).

As already noted, there are (at least) three ways of explaining the reasons for some or all Old Irish alternations.

One, advocated by Thurneysen (1946: 96ff.), is that Old Irish consonants were specified by three qualities, $i, a$ and $u$, as a result of which the word-forms such as [ $\left.\mathrm{f}^{\mathrm{i}} \mathrm{r}^{\mathrm{a}}\right]$ and [ $\mathrm{son}^{\mathrm{a}}$ ] ended in $a$-quality consonants which supplied the element (A) to the preceding vowel, to translate Thurneysen's views into the GP jargon. This standpoint somewhat tallies with that employed in the contemporary analyses of Irish dialects. Specifically, the final consonant of the monosyllabic word contributes to the quality of the preceding vowel. Since (I) and (U) do not combine in Irish, the result is simple: the symbol $u$ has no impact on the quality of the preceding front vowel, the symbol $i$ cannot influence the back vowel, while the symbol $a$ alters the shape of the front/back vowel it follows. We know that $(\mathrm{A}+\mathrm{I})$ equals $[\mathrm{e}]$, while $(\mathrm{A}+\mathrm{U})$ results in [o]. Hence, synchronic derivation takes place in Old Irish and Thurneysen's analysis works for (11a, b). Turning to the changes in (11c), Thurneysen (1946: 50) finds them inexplicable, while those in (11d) are perceived by him (1946: 53) as replacements of the original [e] by [a] before palatalised consonants, which is difficult to comprehend.

The second approach, supported by McCone (1996), is radically different. The consonants are viewed to have only two values: palatalised (i-quality) and neutral ( $o, a$, ?-quality), while the dative forms such as those spelt with -iu-, e.g. fiur, should be recognized as ones with short diphthongs, i.e. [fiur]. Thus, the neutral quality influences the forms such as the nominative, e.g. $\left[\mathrm{f}^{\mathrm{i}} \mathrm{er}^{\mathrm{a} / \mathrm{o}}\right]$, but it has no impact on those of the dative, which displays the diphthong. Again, the approach is synchronically derivational since the basic form is exposed to external forces secured by the final consonant and, in fact, this analysis is capable of explaining what happens to the forms in (11a) but has nothing (more than Thurneysen's) to say about those in (11b). Almost, but not exactly the same can be said about the forms in (11c, d), because McCone (1996: 118ff.) offers a 
convincing reconstruction of the prehistoric development of words like [dar $\left.{ }^{i}\right]$ vs. [d ${ }^{i}$ eyo], which points to the seemingly incomprehensible synchronic lowering of the root vowel [e] to [a] in the nominative singular, which is, diachronically, a move in the right direction. To sum up, in his analysis McCone partly dispenses with the idea that phonology was dominant in shaping the Old Irish vowels. Given his abundant knowledge of what was going on in the prehistory Irish, this seems too modest a step.

According to the third view (Jaskuła 2006), it does not matter what and how many consonant qualities there were in use in Old Irish synchronically. All the short vowels in stressed syllables, i.e. the first vowels in words, were diachronically determined and phonology played no crucial part in shaping them synchronically. Consequently, since there was little phonology per se in contrast to the morphophonology ${ }^{6}$ in the phonology of Old Irish, what should be looked at while considering vowel alternations is the prehistoric forms of words. The examination of what happened long BEFORE Old Irish will shed more light on what was going on IN the Old Irish vocalic system.

\section{Old Irish Vocalic Alternations - Analysis Three}

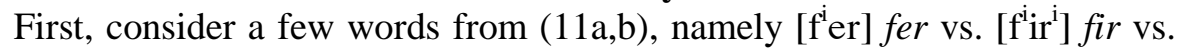
[ $\mathrm{f}^{\mathrm{i}} \mathrm{ir}$ ] fiur - 'man'/gen.sg./ dat.sg., representing the change [i - e], as well as [son] son vs. [sun'] suin vs. [sun] sun - 'sound'/gen.sg./dat.sg., illustrating the alternation of $[\mathrm{u}-\mathrm{o}]$. What can be proposed instead of looking for the synchronic causes of these changes is looking back upon their prehistoric derivations:

(12)
a. *wirah $\rightarrow \quad *$ wera $\rightarrow \quad$ [fier] fer
*wiri: $\rightarrow \quad *$ wiri $\rightarrow \quad\left[\mathrm{f}^{\mathrm{i} i \mathrm{ir}}\right.$ ] fir
*wiru: $\rightarrow \quad *_{\text {wiru }} \rightarrow$ [fir] fiur
b. *sunah $\rightarrow$ *sona $\rightarrow$ [son] son
*suni: $\quad \rightarrow \quad$ *suni $\quad \rightarrow \quad$ [sun'] suin
*sunu: $\quad \rightarrow \quad *_{\text {sunu }} \quad \rightarrow \quad$ [sun] sun

These reconstructions, based upon Thurneysen (1946) and McCone (1996) show that the original vowels [i] in (12a) and [u] in (12b) were regularly lowered to [e] and [o], respectively, before the vowel [a] in the following syllable. In terms of GP, the element (A) in the ending spread to the root vowel to cause its lowering. If the ending was either $[\mathrm{u}]$ or [i], no change ever took place. Therefore, the reason for the alternations of [i $-\mathrm{e}]$ and $[\mathrm{u}-$

\footnotetext{
${ }^{6}$ Morphophonology is treated here as the petrification of past phonological patterns in present phonological systems.
} 
o] should not be searched for in Old Irish but before that period. These changes are simply the long-lasting effects of what happened in prehistory.

Given these explanations, let us turn to the word [ $\left.\mathrm{R}^{\mathrm{i}} \mathrm{iNd}\right]$ rind - 'star', whose prehistoric shape was $* \mathrm{R}^{\mathrm{i}} \mathrm{iNdu}$ and whose oblique cases shown in (11a) are regular. However, there is also the genitive plural [ $\mathrm{R}^{\mathrm{i}} \mathrm{N}$ de] rendae, which, according to the synchronically-phonological standards described under (11), should surface as $*\left[\mathrm{R}^{\mathrm{i}} \mathrm{iNde}\right]$, because [e] did not lower the original high vowel, as shown by $\left[g^{i} l^{i} e N\right]$ glenn vs. $\left[g^{i} l^{i} i^{i} e\right]$ glinne - 'valley'/gen. sg. or [mur'] muir vs. [mur'e] muire - 'sea'/acc.pl. As argued by Thurneysen (1946: 198) and Pokorny (1914: 64), the original form of the gen.pl. was *rindowom $\rightarrow$ *rendowom $\rightarrow$ *rendo, which ultimately surfaced as [R $\left.\mathrm{R}^{\mathrm{i}} \mathrm{Nde}\right]$ in Old Irish. Thus, what actually happened to this word-form on its way from the prehistory to Old Irish was (i) the lowering of the original stem vowel [i] to [e] due to the presence of [o] in the following syllable and (ii), the replacement of the original ending [o] by [e]. Here again the element (A) included in the vowel [o] influenced the quality of the stem vowel, while [e] was a straw-man. So, the Old Irish final vowel seems to have little impact on the quality of the stem vowel, i.e. the reason for the presence of [e] here is not phonological because [e] in the ending never had any effect on the preceding vowel.

Moreover, there are Old Irish stem vowels which refuse to alternate although they find themselves in contexts perfect for change, e.g.

a. [muk] mucc [mukie] muicce [muka] mucca - pig'/gen.sg./acc.pl.

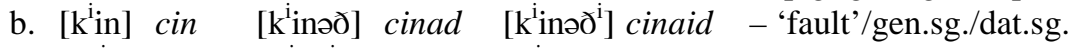

c. [L $\left.{ }^{\mathrm{i}} \mathrm{e} \theta\right]$ leth $\left[\mathrm{L}^{\mathrm{i}} \mathrm{e} \theta^{\mathrm{i}}\right]$ leith $\left[\mathrm{L}^{\mathrm{i}} \mathrm{e} \theta\right]$ leuth - 'half'/gen.sg./dat.sg.

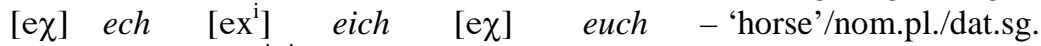

d. [korp] corp [kor $\left.\mathrm{p}^{\mathrm{i}}\right]$ coirp [korp] corp - 'body'/gen.sg./dat.sg.

e. [mak] macc [mak'] maicc [mak] macc - 'boy'/gen.sg./dat.sg.

As for (13a, b), one might wonder why the stem vowels do not change into [o] in the accusative plural [muka], or into [e] the in the genitive [ $\mathrm{k}^{\mathrm{i} i n ə \partial]}$ or dative $\left[\mathrm{k}^{\mathrm{i} i n} \gamma^{\mathrm{i}}\right]$. The answer may be that these stem vowels are phonologically different from those in [son] son vs. [sun] sun 'sound'/dat.sg. and [ $\left.\mathrm{R}^{\mathrm{i}} \mathrm{iNd}\right]$ rind vs. [ $\mathrm{R}^{\mathrm{i}} \mathrm{eNdo}$ ] rendo - 'star'/gen.sg. Indeed, they behave differently, but the next question is: when are they different? Given the explanation of [RieNde] rendae - 'star'-gen.pl. above, the answer is not so certain.

Turning now to (13c), it must be observed that the vowel [e] of the nominative $\left[\mathrm{L}^{\mathrm{i}} \mathrm{e} \theta\right.$ ] does not change in the oblique cases, we even find forms such as the genitive singular $\left[\mathrm{L}^{\mathrm{i}} \mathrm{e} \theta^{\mathrm{i}} \mathrm{e}\right]$ leithe, which seems to point to a 
confusion of endings in Old Irish, i.e. the endings typical of some stems were replaced by those of other stems. But in the word for 'horse' we find an alternative nom.pl. [ix $\left.{ }^{\mathrm{i}}\right]$ ich, which may mean that the original vowel [e] was reinterpreted in this phonological system in two ways: either as an alternating vowel or as a stable segment.

These observations are reinforced by the cases in (13d), where the stem vowel [o] does not change, but where we can also find the much less frequently attested genitive [kur $\left.{ }^{i} p^{i}\right]$ cuirp, and dative [kurp] curp. Therefore, it seems that some dissimilar vowels from BEFORE Old Irish were reinterpreted WITHIN Old Irish as similar or identical phonetically but not phonologically. In particular, some speakers treated [o] as nonalternating while others as one which does change. ${ }^{7}$

When we turn to the stem vowel [a] in (13e), it refuses to change into either [u], as that in (11c), or into [e], as that in (11d). Is this a different vowel? If it is, when is it different? We will soon see that this vowel is fairly normal since its alternations with other vowels are by and large unusual.

Thus, this brings us to the question of how many vowels can be assumed to have diverse phonological structures from a synchronic perspective. In other words, we must consider the issue of likelihood. Obviously, it is not uncommon in languages that some identical segments or phonetic objects have dissimilar phonological provenance (see e.g. Gussmann 2001), but here we are faced with the question of scale. What needs to be assessed is whether it is possible for all the short vocalic expressions of a given language to be phonologically diverse. And the answer to this is, necessarily: well, this is peculiar.

Before we reach any final conclusions, let us consider again the vowel [a], which may change in two different ways depending on its interpretation. We must first return to the alternation of $[\mathrm{a}-\mathrm{u}]$ shown in (11c) above:

$\begin{array}{llll}\text { (14) Nominative SG. } & \text { GENITIVE SG. } & \text { DAtive SG. } & \text { Gloss } \\ \text { STANDARD }[\mathrm{kraN}] \text { crann } & {\left[\mathrm{kruN}^{\mathrm{i}}\right] \text { cruinn }} & {[\mathrm{kruN}] \text { crunn }- \text { 'tree' }} \\ \text { LATER/ EARLIER } & {\left[\mathrm{kraN}^{\mathrm{i}}\right] \text { crainn }} & {[\mathrm{krauN}] \text { ? craunn }}\end{array}$

A word of explanation suffices. The gen. sg. crainn is standard Middle Irish, but it seems that this form must have had an earlier, albeit apparently unattested (dialectal?) precedent. The vowel [u] in the dative was formerly the diphthong [au] according to Greene (1976: 29), hence craunn is proposed above. Thus, the seemingly standard alternation $[\mathrm{a}-\mathrm{u}]$, is rather

\footnotetext{
${ }^{7}$ It is not unlikely that such variations are dialectal, which is rather impossible to determine.
} 
hard to explain in terms of synchronic phonology, since the root vowel of the nominative is simply replaced by another one in the other cases. But answering the question of when this alternation takes place may be helpful in accounting for this change quasi-phonologically.

Consider the following reconstruction of these word-forms based on Lewis and Pedersen (1974: 103) and developed by Jaskuła (2006: 200201):
a. ${ }^{*} \mathrm{k}^{\mathrm{w}} \mathrm{rnnnan}$

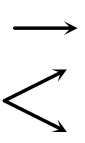
$[\mathrm{p}]=[\mathrm{a}] \rightarrow{ }^{*} \mathrm{kraNa} \rightarrow[\mathrm{kraN}] \quad$ crann
$[\mathrm{p}]=[\mathrm{o}] \rightarrow{ }^{*} \mathrm{kruNi} \rightarrow\left[\mathrm{kruN}^{\mathrm{i}}\right] \quad$ cruinn
b. ${ }^{*}{ }^{\mathrm{w}}{ }^{\mathrm{r}}$ nnni:
$[\mathrm{p}]=[\mathrm{a}] \rightarrow{ }^{*} \mathrm{kraNi} \rightarrow\left[\mathrm{kraN}^{\mathrm{i}}\right] \quad$ crainn
$[\mathrm{p}]=[\mathrm{o}] \rightarrow{ }^{*} \mathrm{kruNu} \rightarrow[\mathrm{kruN}] \quad$ crunn
c. ${ }^{*} \mathrm{k}^{\mathrm{w}} \mathrm{rnnnu}$

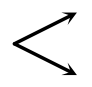

$$
[\mathrm{p}]=[\mathrm{a}] \rightarrow{ }^{*} \mathrm{kra}(\mathrm{u}) \mathrm{Nu} \rightarrow[\mathrm{kra}(\mathrm{u}) \mathrm{N}] \text { craunn }
$$

The state of affairs in (15a) is clear: the prehistoric low [p] was at some stage of development reinterpreted as a kind of [a] or, perhaps [a]. ${ }^{8}$ When we turn to (15b), the same [p] was interpreted either as [o], which gave rise to the typical alternation $[\mathrm{o}-\mathrm{u}]$, i.e. we ultimately have $\left[\mathrm{kruN}^{\mathrm{i}}\right]$, or as $[\mathrm{a}]$, which is normally a stable vowel, as a result of which we encounter the form $\left[\mathrm{kraN}^{\mathrm{i}}\right]$. In (15c) the situation is the same in the first part, where the reanalysis of $[\mathrm{p}]$ as [o] triggers the change to $[\mathrm{u}]$ in the standard dative. If the original vowel is realised as [a], the dative might be realised as [krauN] or [kraN]. A similar situation can be observed in [baL] ball - 'limb', whose genitive is either baill or boill, the dative being baull or bull (Thurneysen 1946: 177).

What this historical derivation shows is that the reasons for the alternation of [a-u] should not be sought in the phonology of Old Irish but a long time before.

The last and most mysterious alternation is [a - e], which is shown in (11d). Recall the classic example of $\left[\mathrm{dar}^{\mathrm{i}}\right]$ daig vs. [deyo] dego 'fire'/gen.sg. The genitive looks as if its vowel alternated with [i], which normally happens in e.g. [ $\left.\mathrm{R}^{\mathrm{i}} \mathrm{iNd}\right]$ rind vs. [ $\mathrm{R}^{\mathrm{i}} \mathrm{eNdo}$ ] rendo - 'star'/gen.sg. But here the nominative vowel is [a] and no logical explanation in terms of synchronic phonology can be offered. McCone $(1996: 111,118)$ presents the following derivations of the forms in question:

\footnotetext{
${ }^{8}$ For the sake of clarity and simplicity, no dates or names of periods in the development of Irish are provided here. Nor is it crucial to decide which phonetic variant of the low vowel was really in use.
} 
(16)
a. $*$ dey $^{\mathrm{w}}$ ih $\rightarrow \quad *$ dæy $^{\mathrm{w}} \mathrm{i} \rightarrow \quad\left[\mathrm{day}^{\mathrm{i}}\right]$
b. $*$ dey $^{\mathrm{w}}$ o:h $\rightarrow \quad * \mathrm{~d}^{\mathrm{i}} \mathrm{ey}^{\mathrm{w}}{ }^{\mathrm{w}} \rightarrow \quad\left[\mathrm{d}^{\mathrm{i}} \mathrm{eyo}\right]$

We can see that in both cases the original stem vowel was [e]. In the genitive in (16b) this vowel never changed and survived also in Old Irish. In the nominative (16a), however, it was gradually lowered to finally surface as [a]. If this reconstruction is correct, the cause of the vowel lowering remains a mystery, but the alternation of [a - e] ceases to look like a synchronic, context-motivated process in Old Irish.

Thus, step by step, it has been demonstrated that the alternations of Old Irish short vowels need not and should not be viewed as phonological processes sensu stricto. In other words, if we assume that a process is phonological if and only if there is a clearly determined phonological context which can trigger this process, then in Old Irish, as well as in the dialects of Modern Irish, such contexts do not habitually occur. Such a situation may not be easy to accept. From the analytical point of view, if we see that there is a root vowel which changes within the paradigm of a given word, we automatically assume that this must happen for a reason and we search for this reason within the system we are given. Alas, this may not be a fortunate decision because some systems prefer morphophonology to phonology or, in other words, they cherish their past.

What routinely arises out of such a conclusion is the question of how we should treat the descendants of such phonological systems. Are they totally independent, partially dependent, or completely slavish towards what they have experienced before?

For if we map the Old Irish diachronically-determined system onto the dialects of Modern Irish, we can see that the flagship examples of the analyses of both Munster and Connemara, e.g. [f $\mathrm{f}^{\mathrm{i}} \mathrm{ar}$ ] fear vs. [f $\mathrm{f}^{\mathrm{i}} \mathrm{ir}^{\mathrm{i}}$ ] fir -

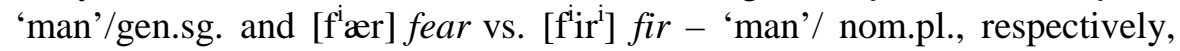
are effortlessly classified as instances of morphophonological alternations not only in Modern but also (and predominantly) in Old Irish. Therefore, the Modern Irish alternations are even more morphophonological and even less phonological than those encountered in Old Irish.

\section{Conclusion}

In this paper it has been demonstrated that what looks truly phonological need not be such. Five analyses of vocalic alternations in the history of Irish have been presented. The twin analyses of Modern Irish dialects (Cyran 1997; Bloch-Rozmej 1998) and the two classic attempts (Thurneysen 1946; McCone 1996) at explaining the phonology of Old Irish are all flawlessly logical and intellectually well-designed but, at the same 
time, they all seem to miss one important point: not everything that occurs within a phonological system of a given language ought to be synchronically accounted for. Alternatively, we may assume that there exist languages and phonological systems whose connections with the past are stronger than it might appear. Thus, whenever we analyse the phonological system of a given tongue, it is always necessary to look back, at least a little.

John Paul II Catholic University of Lublin, Poland

\section{References}

Bloch-Rozmej, A., 1998, Element Interactions in Phonology. A Study in Connemara Irish, Lublin: Redakcja Wydawnictw KUL.

Charette, M., 1990, 'Licence to Govern', Phonology 7, 233-253.

Cyran, E., 1997, Resonance Elements in Phonology. A Study in Munster Irish, Lublin: Folium.

Greene, D., 1976, ‘The Diphthongs of Old Irish', Ériu 27, 26-45.

Gussmann, E., 2001, 'Hidden Identity, or the Double Life of Segments', in: K. Dziubalska-Kołaczyk, ed., Constraints and Preferences, Berlin: Mouton de Gruyter, 229-249.

Gussmann, E. \& Kaye, J., 1993, 'Polish Notes from a Dubrovnik Café: I. The Yers', SOAS Working Papers in Linguistics and Phonetics 3, 427462.

Harris, J., 1994, English Sound Structure, Oxford: Blackwell.

Jaskula, K., 2006, Ancient Sound Changes and Old Irish Phonology, Lublin: Wydawnictwo KUL.

Kaye, J., Lowenstamm, J. \& Vergnaud J-R., 1990, 'Constituent Structure and Government in Phonology', Phonology 7, 193-231.

Lewis, H. \& Pedersen, H., 1974, A Concise Comparative Celtic Grammar, Göttingen: Vandenhoeck and Ruprecht.

McCone, K., 1996, Towards a Relative Chronology of Ancient and Mediaeval Celtic Sound Change, Maynooth: St. Patrick's College.

Pokorny, J., 1914, A Concise Old Irish Grammar and Reader, Halle: Max Niemeyer, Dublin: Hodges, Figgis \& Co., Ltd.

Thurneysen, R., 1946, A Grammar of Old Irish, Dublin: The Dublin Institute for Advanced Studies. 